\title{
Quantitative phenotypic and functional analyses of islet immune cells before and after diabetes onset in the BB rat*
}

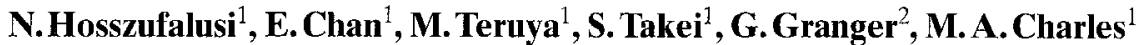 \\ ${ }^{1}$ Diabetes Research Program, University of California, Irvine, California, USA \\ ${ }^{2}$ School of Biological Sciences, University of California, Irvine, California, USA
}

\begin{abstract}
Summary. Inflammatory cells invading islets are thought to be mediators of islet destruction in spontaneous autoimmune diabetes mellitus. Thus methods were developed to isolate and characterize in situ islet inflammatory cells from 75-95day-old prediabetic and diabetic BB rats. Islet inflammatory cells were structurally examined using single- and doublecolour flow cytometry. Functional studies consisted of cytolytic assays using normal rat islet target cells and in situ islet or spleen effector cells. Structural data reveal natural killer cells to be the major cell population $(70 \%)$ of total immune cells present in inflamed islets during prediabetes. At diabetes onset, the natural killer cell population remained at a high level (47\%), but an increasing population of $\mathrm{T}$ cells $(40 \%)$ was noted also. Analyses of T-cell subsets before and after diabetes onset revealed $\mathrm{CD} 4^{+} \mathrm{T}$ cells as predominant $(50-55 \%$ of total $\mathrm{T}$ cells) with double-negative (CD4-
\end{abstract}

CD8 $\left.{ }^{-}\right) \mathrm{T}$ cells (25-30\%) and CD8 ${ }^{+} \mathrm{T}$ cells $(15-20 \%)$ also present in significant quantities. Activated $\mathrm{T}$ cells accounted only for a minority of $\mathrm{T}$ cells $(<3 \%)$. Functional studies indicate that in situ islet-derived cytolytic effector cells are more potent killers (ten-fold) of normal islet target cells than are splenic effector cells. These data suggest that in situ islet inflammatory cells (a) can be quantitatively studied both structurally and functionally; (b) express structural phenotypes differing substantially from splenic mononuclear cell populations; (c) are considerably more cytolytic than splenic effectors; and (d) should prove informative in determining the most significant autoimmune functional events prior to and during islet beta-cell destruction.

Key words: BB rat, in situ islet immune cells, inflamed islets, diabetes mellitus, islets.
Immune infiltrating cells in pancreatic islets are thought to cause destruction of beta cells, leading to diabetes onset. Using semiquantitative methods such as immunohistochemistry of pancreas tissue, several immune cell types have been described to spontaneously occur in the diabetic-prone BB rat islets or pancreas [1-7]. The in situ islet infiltration of specific cell types is time-dependent $[1,5,6]$. Early infiltrating cells in this process are dendritic cells and macrophage, followed by $T$ cells, natural killer (NK) cells and later by B lymphocytes [1, 4-7]. These semiquantitative analyses suggest that just prior to or after diabetes onset, the relative percentages of in situ islet mononuclear cells follow the hierarchy of dendritic cell/macrophage, $\mathrm{CD} 4^{+} \mathrm{T}$ cells, similar or lesser numbers of $\mathrm{CD} 8^{+} \mathrm{T}$ cells, and finally NK cells [3-7]. Activated $T$ cells are also suggested to be present in the $B B$

\footnotetext{
* This work was reported in part at the European Association for the Study of Diabetes in Copenhagen, Denmark, in September, 1990 and at the International Diabetes Federation Congress in Washington DC, June, 1991
}

rat pancreas or islets $[2,3]$. The above-mentioned studies in BB rats are difficult to interpret quantitatively because of the cross-reactivity of monoclonal antibodies to multiple mononuclear subsets, e.g. W3/25 reactivity with $\mathrm{CD} 4^{+} \mathrm{T}$ cells, macrophage and dendritic cells. Specific combinations of double-antibody staining could be used to avoid such cross-reactivity. Finally, these semiquantitative approaches do not permit concomitant population-based in situ islet mononuclear cell functional studies.

More quantitative and specific methods to structurally analyse islet-infiltrating mononuclear cells are needed to determine which cells are functionally pathogenic. Further, quantitative islet analyses permit comparisons with other lymphoid organs such as blood and spleen. For example, we have recently surveyed BB rat spleen cell types quantitatively in detail [8]. These data indicate that in the lymphopoenic diabetic-prone BB rat spleen, both before and after diabetes onset, the following hierarchy of cell composition exists: B lymphocytes (40\%); macrophage $(30 \%)$; T cells $(20 \%)$; and NK cells $(10 \%)$. This 
composition for all cell types, except B lymphocytes, is strikingly different from normal Wistar Furth rats or BB rats of the non-lymphopoenic diabetes-resistant strain. Further, analyses of splenic T-cell subsets indicate that percentages of double-negative $\left(\mathrm{CD} 8^{-} \mathrm{CD} 4^{-}\right)$and activated $T$ cells represent major cell populations. It is then necessary to determine how spleen mononuclear cell composition relates to in situ islet-infiltrating mononuclear cell composition. The latter should be more directly related to disease onset and thus more relevant for spontaneous pathogenesis studies. We now report quantitative and specific methods for the isolation and characterization of in situ islet-infiltrating immune cells permitting systematic phenotypic and functional studies in the $\mathrm{BB}$ rat. We have recently reported similar data in the nonobese-diabetic (NOD) mouse [9]. Our data in both diabetic models provide new insights that represent a distinct departure from quantitative spleen data or semiquantitative islet and pancreas data derived using immunohistochemical methods to assess the pathogenesis of islet destruction.

\section{Materials and methods}

Animals. Adult male Sprague Dawley rats were obtained from Simonsen Laboratory (Gilroy, Calif., USA). Diabetes-resistant Wistar rats (DR, 75-95 days of age), diabetic-prone (DP, 75-95 days of age) and diabetic ( $\mathrm{D},<6$ days since onset of disease) male $\mathrm{BB}$ rats were kindly provided by Dr. P. Thibert (Animal Resources Division, Sir Frederick Banting Research Centre, Ottawa, Ontario, Canada). Animals were defined as diabetic if urine glucose was greater than $0.25 \%$ (Tes-Tape; Eli Lilly, Indianapolis, Ind., USA) and non-fasting blood glucose was greater than $13.8 \mathrm{mmol} / \mathrm{l}$. All animals were fed standard laboratory rat chow pellets and tap water ad libitum. From ongoing studies, the incidence of diabetes in BB rats in our vivarium setting is $51 \%$ based on 280 rats followed for 240 days: The frequency of islet inflammation in non-diabetic DP rats is greater than $85 \%$ at 90,130 and 240 days of age. In diabetic rats all animals have islet inflammation, and peak diabetes incidence rates are observed between $80-100$ days of life, by which time $80 \%$ of animals who will acquire diabetes are diabetic. For non-diabetic and diabetic DP rats, islets from 8-15 animals were pooled for each fluorescent antibody cell sorter (FACS) or cytolytic assay in order to isolate sufficient immune cells for study.

Islet isolation. This method has been previously described in detail [10]. In brief, rats were anaesthetized using $50 \mathrm{mg} / \mathrm{kg}$ body weight of sodium-pentobarbital i.p. (Nembutal; Abbott Laboratories, Chicago, Ill., USA), the distal common bile duct was ligated and the pancreas was infused with $20 \mathrm{ml}$ of Hank's balanced salt solution (HBSS) containing $0.02 \%$ bovine serum albumin (BSA, Fraction V, Sigma, St. Louis, Mo., USA) and $2 \mathrm{mmol} / \mathrm{l}$ glucose at $\mathrm{pH}$ 7.40. The pancreas was excised, minced and digested with collagenase (Sigma, Type V) at $37^{\circ} \mathrm{C}$ for about 20 min. Islets were purified manually using a dissection microscope and a micropipette to avoid contamination with lymph nodes and pancreatic exoctine tissue. For successful islet isolation from $\mathrm{BB}$ diabetic animals, the procedure must be performed within $0-4$ days after the onset of diabetes.

Islet single cell preparation. Islet single cells were isolated from freshly isolated rat islets using a method previously described [11]. Briefly, islets were dispersed into single cell suspensions by incubation in $200 \mathrm{Lg} / \mathrm{mI}$ DNAse (Sigma) in Swim's low calcium medium (Gibco, Grand Island, NY, USA) containing $1 \mathrm{mmol} / \mathrm{l}$ EGTA (Sigma) and $1 \% \mathrm{BSA}$. The dispersed cells were washed three times with RPMI 1640 (Gibco) containing 10\% fetal calf serum (FCS, Gibco). After washing, the cell number (islet immune cells, endocrine and stromal cells) was counted and viability was checked using trypan blue. Cell viability was greater than $90 \%$.

Isolation of splenic mononuclear cells. Spleen was excised from anaesthetized rats and splenic cells were "dispersed" from spleen using HBSS deficient in $\mathrm{Ca}^{+2}$ and $\mathrm{Mg}^{-2}$. Splenic mononuclear cells were isolated by Ficoll-hypaque (Lymphocyte Separation Medium; Organon Teknika, Durham, NC, USA) as previously described [12]. Cell viability was greater than $95 \%$. An antibody binding panning method was used to enrich spleen cell lymphoid and mononuclear cell subpopulations. This method is used to positively or negatively select specific lymphocyte subpopulations based on their cell surface markers and is previously described in detail [13]. Total spleen mononuclear cells $\left(10^{7} / \mathrm{ml}\right)$ are incubated for $1 \mathrm{~h}$ at $5^{\circ} \mathrm{C}$ in petri dishes (maximum volume $4 \mathrm{ml}$ ) coated with affinity purified goat anti-rat IgG (heavy and light chains specific, Organon Teknika) to remove macrophages and $B$ lymphocytes. The nonadherent cells ( $\mathrm{T}+\mathrm{NK}$ cells) are then incubated for $20 \mathrm{~min}$ at $23^{\circ} \mathrm{C}$ with various mouse anti-rat $\mathrm{T}$-cell subset monoclonal antibodies, washed and then transferred into petri dishes precoated with affinity purified goat anti-mouse IgG (heavy and light chains specific). Adherent and nonadherent cells for the specific monoclonal antibodies (same monoclonals as described below in FACS studies) are collected after incubation at $5^{\circ} \mathrm{C}$ for $2 \mathrm{~h}$. The purity of the specific cell subpopulations is determined by phenotyping using FACS, as described below in cell staining.

Cell staining. Rat splenic mononuclear cells and single cells isolated from islets were washed twice with staining buffer containing phosphate buffered saline (Sigma), 1\% BSA (Sigma) and 0.02\% sodium azide (Fisher Scientific Company, Fair Lawn, NJ, USA). For identifying NK cells, incubation with mouse mAb, fluorescein-isothiocyanate (FITC) conjugated 3.2 .3 (anti-CD16) for 60 min was performed [14]. For identifying macrophage, an indirect staining method was used: cells were incubated for $60 \mathrm{~min}$ with $\mathrm{OX} 41$ (mouse anti-rat macrophage, granulocyte and dendritic cell), washed twice with staining buffer, and incubated with a second antibody, rat cell absorbed FITC-conjugated goat anti-mouse IgG, (Caltag Laboratories, San Francisco, Calif., USA), for $30 \mathrm{~min}$. For direct two-colour staining of total $\mathrm{T}$ lymphocytes. T-lymphocyte subsets and activated $T$ cells, cells were incubated for $60 \mathrm{~min}$ with mouse mAbs R-7.3-FITC (anti-T cell receptor [TCR] alpha/beta), OX39-FITC (anti-interleukin [IL]-2R) or OX6-FITC (anti-RT1B MHC, class II monomorphic). After incubation, cells were washed twice with staining buffer and incubated with phycoerythrin (PE) conjugated OX19 (anti-CD5) or W3/25-PE (anti-CD4) for $60 \mathrm{~min}$ or with OX8-PE (anti-CD8) for $30 \mathrm{~min}$. For measuring doublenegative cells, cells were incubated first with R-7.3-FITC $\mathrm{mAb}$ for $60 \mathrm{~min}$, washed twice with staining buffer, and incubated with W3/25-PE for $60 \mathrm{~min}$ and with OX8-PE for $30 \mathrm{~min}$. For staining B lymphocytes, cells were incubated for $30 \mathrm{~min}$ with OX12-PE (antirat kappa chain). All incubations were performed on ice, in the dark, using 0.05-0.2 $\times 10^{6}$ cells, and all mAbs (Serotec, Oxford, $\mathrm{UK}$ ) were used at saturating concentrations. After the last incubation with antibody, cells were washed twice with staining buffer and fixed in $1 \%$ paraformaldehyde. For direct staining, background was determined by incubation of cells in staining buffer without $\mathrm{mAb}$ or by incubations with purified isotype-matched mouse IgG conjugated with FITC or PE. For indirect staining, the background was determined by incubation of cells in staining buffer containing only secondary antibody conjugated with FITC or with isotypematched mouse IgG.

Flow cytometric analysis. Stained and fixed cells were analysed with a Becton Dickinson (San Jose, Calif., USA) FACScan using a C30 software program (Becton Dickinson). For analysis 10000 cells were collected. For spleen mononuclear analysis, a gate was designed to exclude contaminating erythrocytes, granulocytes and debris. For each in situ single islet cell preparation, the gate used excluded $97 \%$ of islet endocrine and stromal cells, which are larger and more granular than immune cells (see Results). The remaining islet endocrine 


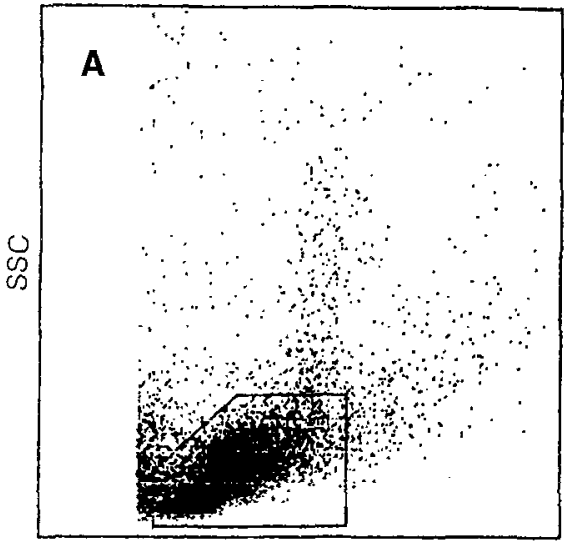

FSC

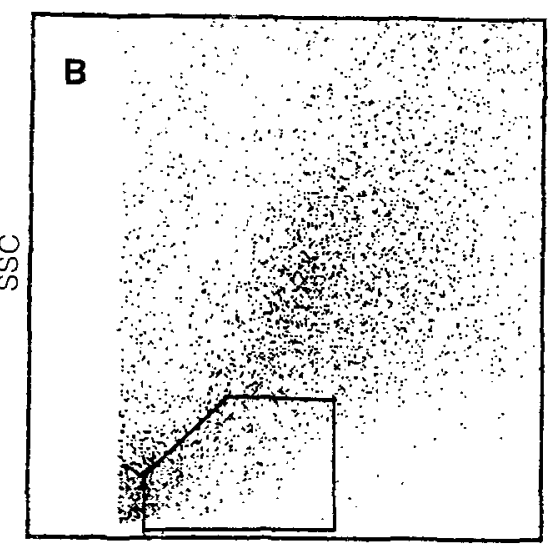

FSC

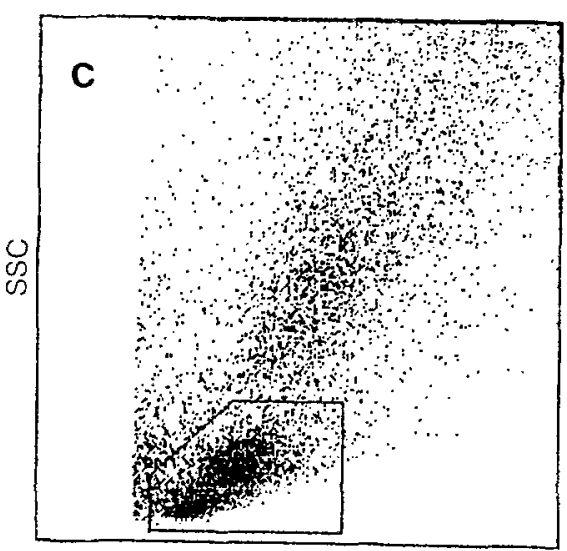

FSC
Fig. 1 A-C. FACS analyses (10000 cell dotplot) of single cells isolated from spleen $(\mathbf{A})$, normal islets $(\mathbf{B})$ or inflamed islets $(\mathbf{C})$. Forward light scatter (FSC) vs side scatter (SSC). The boxed-in area or mononuclear cell gate inset in each panel represent all splenic mononuclear cells with less than $15 \%$ of cells out of the gate in $\mathbf{A}$ consisting of erythrocytes, neutrophils and debris. B shows less than $3 \%$ normal islet endocrine and stromal cells in the mononuclear cell gate, and $\mathbf{C}$ shows inflamed islet single cells with a large number of cells within the mononuclear cell gate which represent virtually all in situ islet immune cells (see Results)

and stromal cells $(<3 \%)$ inside the mononuclear cell gate did not interfere with immune cell phenotyping. Results are displayed in either density graphs or histograms.

Cytolytic assays. This procedure has been previously described in detail [11]. Five thousand ${ }^{51} \mathrm{Cr}$-labelled normal (unless otherwise stated) rat islet target cells were incubated with in situ islet or spleen immune effector cells derived from diabetic or non-diabetic $\mathrm{BB}$ rats in polyethylene tubes for $16 \mathrm{~h}$ at $37^{\circ} \mathrm{C}$. Several effector: target ratios were used. In some experiments target cells from Wistar Furth rats were used. For non-islet target cell killing assays, intestinal epithelial cell line 18 (IEC) were used. This line was originally purchased from American Type Culture Collection (Rockville, Md, USA), and these cells were derived from rat ileum epithelia [15]. One-week-old confluent monolayer cultures were detached by trypsinization, washed and labelled with $0.1 \mathrm{mCl}$ of ${ }^{51} \mathrm{Cr}$ and incubated at $37^{\circ} \mathrm{C}$ for $1 \mathrm{~h}$. In each tube $5 \times 10^{3}$ cells were used for the cytolytic assay. For all target and effector cell types, an effector : target ratio of $5: 1,2.5 \times 10^{4}$ effector cells were mixed with the $5 \times 10^{3}$ target cells. After incubation, the supernatant was assessed for ${ }^{51} \mathrm{Cr}$ release using a gamma counter. Cytolysis from Triton X-100 treated labelled target cells was $100 \%$, and spontaneous release was $20-25 \%$. Cytotoxicity from triplicate determinations was averaged and specific cytotoxicity calculated.

\section{Statistical analysis}

All mean data \pm SEM were compared using an unpaired Student's t-test. One experiment $(n=1)$ for both phenotypic and cytolytic studies included 50-300 islets from one animal and 8-15 animals pooled for use in each experiment. Thus for diabetic animals, about 500 islets were obtained from 5-10 animals. The islets were pooled and dispersed into single cells, and then inflammatory cells were isolated for analysis in an experiment $(n=1)$. For non-diabetic DP animals, 10-15 animals were used. Three thousand islets were isolated and dispersed, and then inflammatory cells were pooled for one experiment $(n=1)$.

\section{Results}

\section{Separation of islet immune cells from endocrine and} stromal cells

To quantitatively determine the relative percentages of major immune cell subtypes in islets derived from nondiabetic and diabetic DP BB rats, islets were isolated, dispersed, and when necessary, treated with rabbit anti-rat islet cell serum (RARICS), complement and Percoll to isolate in situ islet immune cells.

For diabetic BB animals, all isolated islets $(\sim 50$ islets per rat) were inflamed. Isolation of islets in diabetic rats is confirmed by histology, perifusion insulin secretion data and islet-insulin content, and these data have been compared with non-diabetic DP rats (with and without inflamed islets) and Wistar Furth rats. These data have been presented elsewhere [16]. Single islet cell preparations isolated from inflamed islets from diabetic animals consisted of less than $60 \%$ islet endocrine or stromal cells and greater than $40 \%$ immune cells. Only $1-2 \times 10^{4}$ cells are used in each experiment, so insulin contents are difficult to measure during these analytic procedures. Since spleen mononuclear cells are smaller and less granular (Fig.1 A) than normal islet endocrine and stromal cells (Fig. 1B), proper gating of the in situ inflamed islet cell suspension (Fig. 1C) during FACS analysis defined a cell population consisting of virtually all islet immune cells and less than $3 \%$ endocrine and stromal cells. All islet immune cells are represented, assuming these cells are similar to the total spleen mononuclear cell population (Fig. $1 \mathrm{~A}$ ). To document that islet endocrine and stromal cells at the concentrations present after separation do not affect the phenotyping of islet immune cells, islet cells were added to spleen cells prior to phenotyping (Table 1). As shown, high islet endocrine cell numbers do not alter islet immune cell analyses.

For the non-diabetic rats of the DP BB strain, $80 \%$ of isolated islets ( -300 islets isolated per rat) showed absent or early stages of inflammation, and less than $20 \%$ showed late stages of inflammation. After islet dispersion in non-diabetic DP rats, the cell population consisted of greater than $95 \%$ endocrine and stromal cells and less than $5 \%$ immune cells. The removal of islet endocrine and stromal cells was necessary to minimize the cross-re- 
activity of these cells with the phenotyping monoclonal antibodies $(\mathrm{mAb})$. In addition to the gating method described above, a second and independent method was also used. Thus dispersed islet cells $\left(1 \times 10^{6}\right.$ total cells $\left./ \mathrm{ml}\right)$ were treated with RPMI-1640 culture medium that consisted of $10 \%$ RARICS and $10 \%$ guinea pig complement. The detailed methods for preparation and functional activity of this cytolytic polyclonal antibody RARICS have been previously described [11]. After incubation at $37^{\circ} \mathrm{C}$ for $45 \mathrm{~min}$, more than $98 \%$ of islet endocrine and stromal cells were lysed, leaving behind viable immune cells. To remove non-viable islet cells, the cell mixture was layered over $30 \%$ Percoll in RPMI-1640 with $10 \%$ FCS and centrifuged for $30 \mathrm{~min}$ at $600 \times \mathrm{g}$. Non-viable cells were found at the medium and Percoll interface, and viable cells were in the pellet. This procedure resulted in a cell population with more than $80 \%$ immune cells and less than $20 \%$ endocrine and stromal cells. With proper flow cytometric gating, only $10 \%$ of the remaining endocrine or stromal cells are within the gate for immune cells (Fig. 1). Cross-reactivity of the endocrine or stromal cells with the phenotyping $\mathrm{mAb}$ was

Table 1. FACS analysis of normal splenic mononuclear cells with and without addition of normal rat islet cells $\mathrm{s}^{\mathrm{a}}$

\begin{tabular}{llc}
\hline Cell type & $\begin{array}{l}\text { 100\% Splenic } \\
\text { mononuclear } \\
\text { cells }\end{array}$ & $\begin{array}{l}30 \% \text { Splenic } \\
\text { mononuclear cells } \\
+70 \% \text { islet cells }\end{array}$ \\
\hline TCR alpha/beta $^{+}$ & 14.2 & 15.0 \\
W3/25 $^{+}$, TCR alpha/beta $^{+}$ & 9.3 & 10.7 \\
OX8 $^{+}$, TCR alpha/beta & \\
W3/25- OX8 & 2.6 & 3.2 \\
TCR alpha/beta $^{+}$ & 3.9 & 5.7 \\
IL-2R $^{+}$, OX19 $^{+}$ & & \\
Class II $^{+}$OX19 & 0.1 & 0.1 \\
OX19 $^{+}$ & 1.1 & 1.3 \\
Class II $^{+}$ & 10.1 & 10.2 \\
OX12 $^{+}$ & 26.0 & 27.7 \\
OX41 $^{+}$ & 38.8 & 34.2 \\
$3.2 .3^{+}$(NK) & 10.4 & 9.4
\end{tabular}

${ }^{a}$ All analyses were performed with 10,000 cells for acquisition with no gate and final analysis using the splenic mononuclear cell gate (see Fig. 1 A) thus avoided. This islet endocrine cell lytic procedure yielded results similar to the FACS gating of immune cells described in diabetic animals. Using pooled DR strain animals, no islet immune cells were observed using either the gating method $(n=1)$ or the RARICS method $(n=1)$. Thus FACS analyses were impossible to perform in the DR strain.

To insure that RARICS did not damage islet immune cells, normal and diabetic spleen cells were treated similarly with RARICS and phenotyping was performed in the absence and presence of the RARICS treatment. As shown in Table 2, RARICS treatment had only a minimal effect on spleen cell phenotyping. The RARICS procedure is optional since the easier gating methods yield similar results. To insure that neither collagenase nor DNAase interfered with islet immune cell phenotypes, diabetic rat spleen cells were also exposed to equal times and temperatures of those enzymes as the islets prior to phenotyping. These results are given in Table 3 . In summary, rat islet endocrine cell interference must be resolved by gating or lysis of endocrine and stromal cells. RARICS was shown to induce no significant artefact for spleen cell phenotypic analyses, and collagenase and DNAase were also shown not to alter spleen cell phenotypes.

\section{Quantitative phenotypes of in situ islet immune cells}

To determine the absolute and relative number of immune cells present in inflamed islets of the BB rat, islets were evaluated using the above-mentioned methods. As shown in Figure 2, percentages of B lymphocytes infiltrating islets are relavitely low and at similar levels both before and after diabetes onset. T-cell percentages increase by more than two-fold after diabetes onset $(p<0.01)$. The percentage of macrophage is relatively low both before and after diabetes onset. NK cell infiltration is markedly augmented to more than 3 times all other subtypes present in the islet infiltrates in non-diabetic DP rats $(p<0.001)$, whereas after diabetes onset, NK cell percentages remain elevated but are similar to T cells $(p=\mathrm{NS})$. An islet NK histogram shows the specificity to 3.2 .3 for NK vs background (Fig. 3). It is also unlikely that another significant cell population is present in in situ islets, since the percentages of cell types described above approach $100 \%$.

Table 2. Effect of anti-islet serum (RARICS) and complement treatment on FACS analysis of spleen mononuclear cells

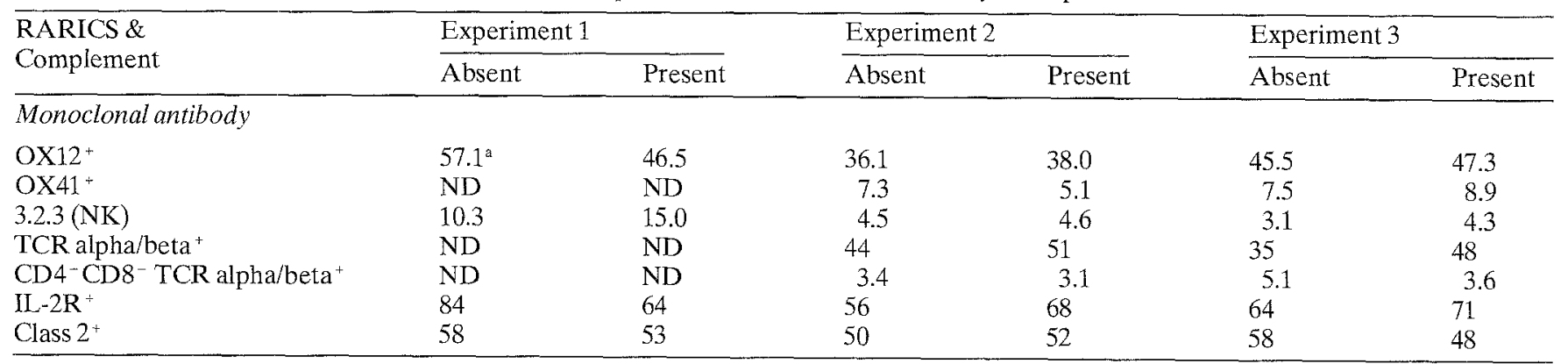

${ }^{a}$ Cells stained as a \% of total cells.

In experiment 1 diabetic animals were used, in experiments 2 and 3 normal animals were used. ND, Not done 
Table 3. Effect of Collagenase-DNAase on FACS analysis of spleen mononuclear cells derived from diabetic $\mathrm{BB}$ rats

\begin{tabular}{|c|c|c|c|c|}
\hline \multirow[t]{2}{*}{ Collagenase-DNAase } & \multicolumn{2}{|c|}{ Experiment 1} & \multicolumn{2}{|c|}{ Experiment 2} \\
\hline & Absent & Present & Absent & Present \\
\hline \multicolumn{5}{|l|}{ Monoclonal antibody } \\
\hline OX12- & $44.6^{\mathrm{a}}$ & 41.2 & 44.7 & 48.2 \\
\hline OX41+ & 18.3 & 20.2 & 20.6 & - \\
\hline $\mathrm{OX} 19^{+}$ & 14.3 & 16.8 & 12.9 & 15.2 \\
\hline $3.2 .3(\mathrm{NK})$ & 12.8 & 14.3 & 12.2 & 10.3 \\
\hline TCR alpha/beta ${ }^{+}$ & 28.4 & 24.3 & 24.1 & 22.1 \\
\hline $\mathrm{CD}^{+}{ }^{+} \mathrm{TCR}$ alpha/beta ${ }^{+}$ & 4.8 & 5.3 & 1.4 & 1.4 \\
\hline $\mathrm{CD}^{+}{ }^{+}$TCR alpha/beta ${ }^{-}$ & 15.7 & 14.9 & 16.4 & 13.7 \\
\hline $\begin{array}{l}\text { CD } 4^{-} \text {CD } 8^{-} \\
\text {TCR alpha/beta }\end{array}$ & 2.1 & 3.7 & 3.1 & 1.5 \\
\hline Class $2^{+}$ & 5.0 & 3.6 & 3.8 & 2.8 \\
\hline
\end{tabular}

${ }^{\text {a }}$ Cells stained as a \% of total cells

T-cell subsets were also quantitatively evaluated in islets derived from non-diabetic and diabetic DP BB rats. These double antibody analyses (Fig. 4) indicate that both before and after diabetes onset, $\mathrm{CD} 4^{+} \mathrm{T}$ cells are the predominant T-cell subtype ( $p<0.01$ vs other subsets). Further, double-negative (DN; $\mathrm{CD}^{-} \mathrm{CD} 8^{-}$, TCR alpha/ beta $\left.^{+}\right) \mathrm{T}$ cells represent the second-largest population of in situ islet $\mathrm{T}$ cells $(p<0.01 \mathrm{vs} \mathrm{CD} 4)$. CD ${ }^{+} \mathrm{T}$ cells are also a significant cell population considering this lymphopoenic rat model ( $p<0.05$ vs CD4 and DN T cells). DN T cells are not low intensity $\mathrm{CD} 8^{+} \mathrm{T}$ cells (Fig. 5), as best illustrated by high and low intensity $\mathrm{CD} 8^{-} \mathrm{T}$ cells observed in spleen cell preparations (Fig.5, panel D). Finally, the presence of activated $T$ cells was examined using two separate antigen expression markers, i. e. anti-Ia and anti-IL2R. Both methods indicate that before and after diabetes onset, activated $\mathrm{T}$ cells, although distinctly present, are not a quantitatively major cell type in islet infiltrates (Fig.4). These subset data also suggest that other TCR alpha/beta ${ }^{+} \mathrm{T}$ cells are not present in islets, since the total percentage of the islet T-cell subsets equals $100 \%$ of TCR alpha/beta ${ }^{+}$cells. Absolute numbers of in situ islet immune cells are presented in Table 4.

\section{Cytolytic activity of in situ islet immune cells}

Since the intrinsic cytolytic activity of islet-infiltrating immune cells has not been reported, we determined the functional behaviour of spontaneously occuring, non immunomodulated islet-infiltrating immune cells. Cytolytic activity was measured using normal Sprague-Dawley rat islet target cells. As shown in Figure 6, in situ islet derived inflammatory effector cells from diabetic or non-diabetic DP BB rats mediated about 10 -fold more cytolysis than effector spleen cells isolated from the same diabetic and non-diabetic animals. Control experiments using nonislet target cells derived from rat ileum showed intermediate cytolytic activity (Fig.6). Control MHC target cell experiments using the Wistar-Furth inbred strain $\left(\mathrm{RT}^{\mathrm{u}}{ }^{\mathrm{u}}\right.$ )

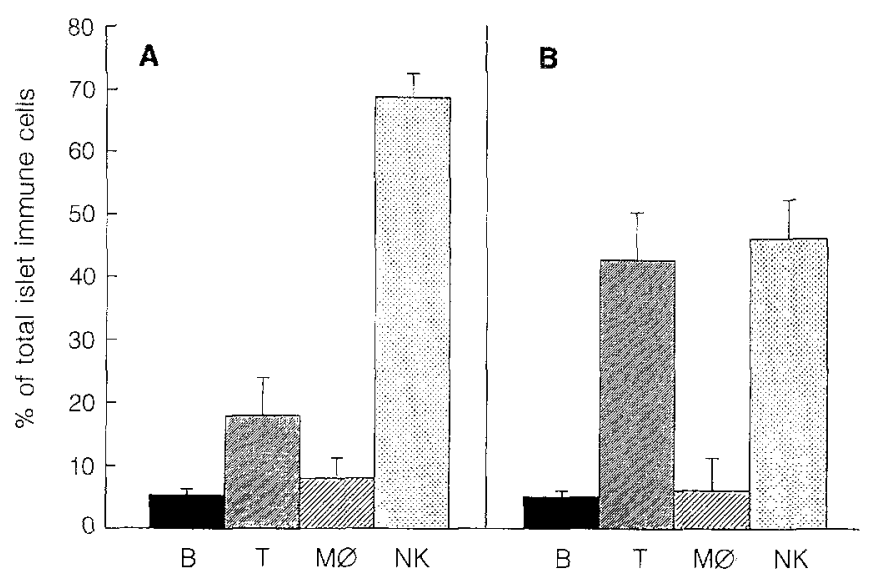

Fig. 2A, B. FACS analyses of BB rat in situ islet immune cells. Cell percentages are shown for $(\mathbf{A})$ diabetes-prone non-diabetic $(n=5)$ and $(\mathbf{B})$ diabetic $(n=5)$ rats. B, B lymphocyte; T, T lymphocyte; $\mathrm{M} \varnothing$, macrophage; NK, natural killer cell

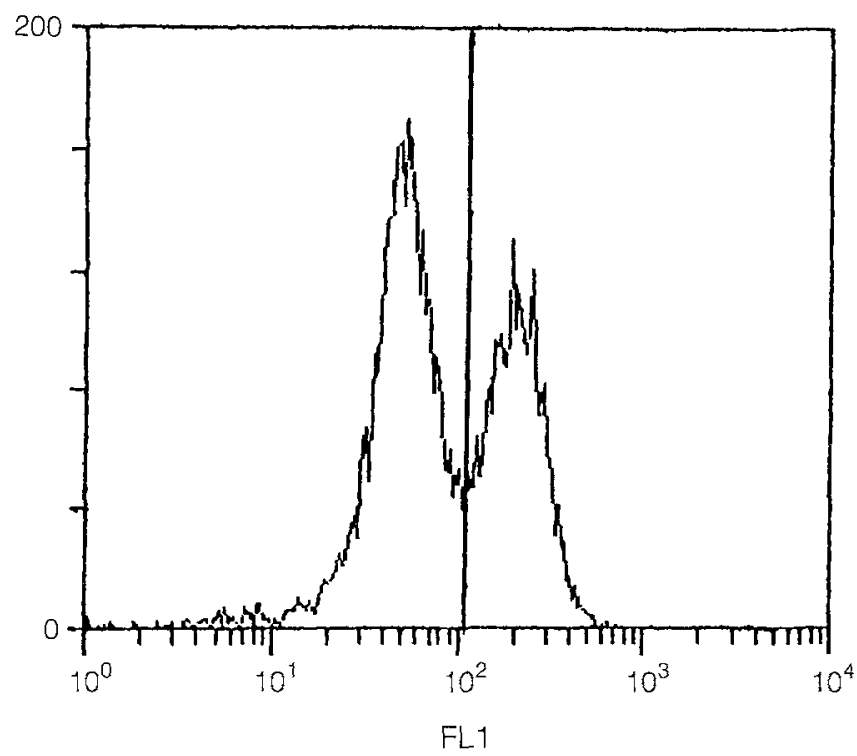

Fig.3. FACS histogram of islet immune cell 3.2.3 staining of natural killer cells derived from diabetic rat. FL 1 refers to fluorescence measured and $y$ axis is number of cells counted

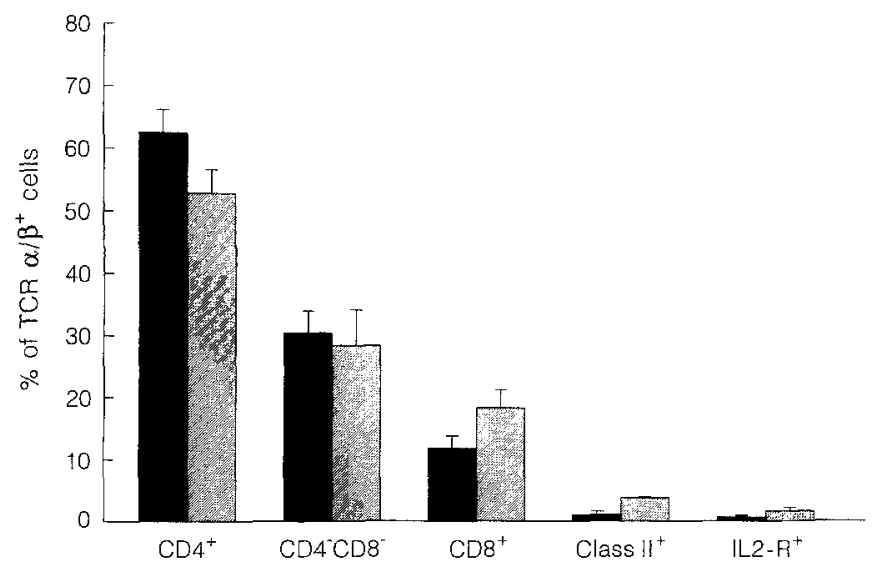

Fig.4. FACS analyses of BB rat in situ islet T-cell subsets in non-

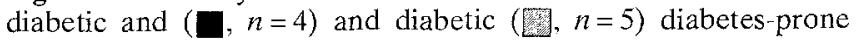
strain. See Materials and methods for monoclonal antibody specificity 

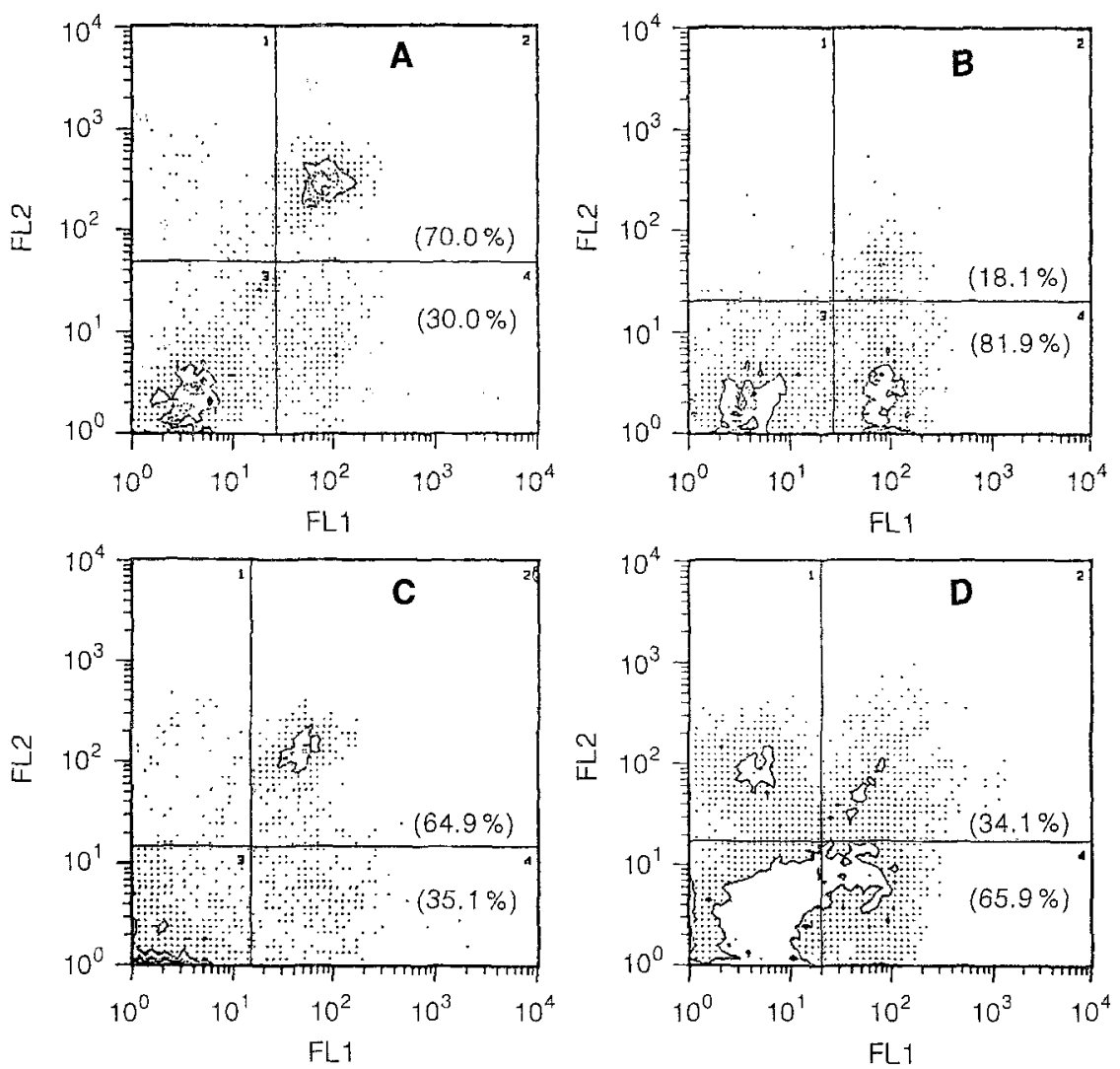

Fig.5A-D. FACS scans of immune cells derived from diabetic rat islets $(\mathbf{A}, \mathbf{B}$ and $\mathbf{C})$ and diabetic rat spleen $(\mathbf{D})$. In all panels TCR alpha/beta reactivity is shown on $x$ axis (FL2) and CD4 (A), CD8 (B and D), or CD4 and $\mathrm{CD} 8$ reactivity $(\mathbf{C})$, are shown on the $y$ axis (FL1). Numbers in parentheses represent $\%$ of TCR $+T$ cells, i.e., quadrants 2 and 4 reflect $100 \%$ of TCR ${ }^{+}$T cells. CD 4 (A, quadrant 2), CD8 ${ }^{+}$(B, quadrant 2) and double negative $\mathrm{T}$ cells ( $\mathbf{C}$, quadrant 4 ) and diabetic spleen: high and low intensity $\mathrm{CD} 8^{+}$ $T$ cells $(\mathbf{D}$, quadrant 2$)$ and $C D 8^{-} T$ cells (D, quadrant 4). This latter diabetic animal spleen result was selected for this panel to emphasize the $\mathrm{CD} 8^{+}$populations since this rat had a higher than usual CD8 ${ }^{+}$T-cell population
Table 4. Absolute numbers of in situ islet immune cells

\begin{tabular}{|c|c|c|}
\hline & $\begin{array}{l}\text { Diabetes-prone } \\
(n=4)\end{array}$ & Diabetic $(n=5)$ \\
\hline B cell & $35 \pm 6$ & $55 \pm 4$ \\
\hline Macrophage & $43 \pm 6$ & $80 \pm 69$ \\
\hline NK cell & $551 \pm 107$ & $478 \pm 61$ \\
\hline T cell & $263 \pm 72$ & $460 \pm 109$ \\
\hline $\mathrm{CD}_{4}{ }^{+} \mathrm{T}$ cell & $170 \pm 59$ & $294 \pm 93$ \\
\hline $\mathrm{CD}^{+} \mathrm{T}$ cell & $34 \pm 17$ & $90 \pm 22$ \\
\hline $\mathrm{CD}^{-}{ }^{-} \mathrm{CD} 8^{-} \mathrm{T}$ cell & $78 \pm 12$ & $146 \pm 55$ \\
\hline Class $2^{+} \mathrm{T}$ cell & $3 \pm 3$ & $19 \pm 8$ \\
\hline IL2-R - T cell & $2 \pm 2$ & $7 \pm 3$ \\
\hline
\end{tabular}

Values are given as mean cell number \pm SEM per islet

islet target cells and total islet immune effector cells derived from DP BB strain rats at a 10:1 effector:target ratio showed high levels of cytolysis at $51 \pm 5.7 \%(n=6)$.

To more precisely define the cytolytic potential of different effector cell types in islets, preliminary studies were performed using spleen cells. Spleen effector cells from non-lymphopoenic (Sprague Dawley) and lymphopoenic diabetic DP-BB rats were evaluated for enrichment using monoclonal antibody and panning methods. Table 5 shows immune cell subset enrichment in both Sprague Dawley and diabetic DP BB rat spleens. Table 5 also shows cytolytic data and levels of enriched $\mathrm{CD} 4^{+}, \mathrm{CD} 8^{+}$, DN T cells and NK cells that were enriched in the DP BB strain by three-fold, two-fold, two-fold and three-fold, respectively. As shown, the cytotoxicity is relatively similar in each enriched preparation. These methods are unsuit- able for islet inflammatory subset cell analysis since only $10^{6}$ immune cells are obtained from islets derived from $12-$ 15 DP strain rats and $10^{8}$ cells were available using BB rats spleen preparations, where enrichment was less than ideal.

\section{Discussion}

Since islet inflammatory cells in the DP strain of BB rats must directly or indirectly lead to beta-cell destruction, we have developed quantitative methods to phenotypically and functionally characterize in situ islet inflammatory cells. The in situ islet results are distinctly different from quantitative spleen results or semiquantitative immunohistochemical islet data derived from non-diabetic or diabetic DP BB rats, but markedly similar to in situ islet T-cell subsets reported in the NOD mouse model [9].

Using the methods described in this report, we have quantitatively presented the immune cells present per islet both before and after diabetes onset. Since all islets are inflamed at diabetes onset, these cell counts appear reasonably accurate. Additional studies were performed to insure that our methods did not distort phenotypic analyses. In non-diabetic DP animals, the absolute cell counts per islet are also reasonable, since all islets studied from any given rat are inflamed. Also, $85-90 \%$ of non-diabetic DP animals have inflamed islets. Another caveat is whether islets derived from diabetic rats reflect the islet destruction process in general, since not all islets can be obtained at this late stage of disease after the islet archi- 
Table 5. Rat spleen effector cell enrichment and islet target cytotoxicity

\begin{tabular}{|c|c|c|c|c|c|c|}
\hline & \multicolumn{2}{|c|}{ Effector cell phenotype (\%) } & \multirow[b]{2}{*}{$\mathrm{DN}$} & \multirow[b]{2}{*}{ NK } & & \\
\hline & $\mathrm{CD} 4$ & CD8 & & & & \\
\hline \multicolumn{7}{|l|}{ Enrichment procedure for: } \\
\hline $\begin{array}{l}\text { Total mononuclear cells } \\
\text { CD }^{+} \mathrm{T} \text { cells } \\
\mathrm{CD}^{\mathrm{a}}{ }^{+} \mathrm{T} \text { cells } \\
\text { Double-negative } \mathrm{T} \text { cells }{ }^{\mathrm{a}} \\
\text { Natural killer cells }\end{array}$ & $\begin{array}{l}27 \pm 3 \\
81 \pm 1 \\
3.1 \pm 0.8 \\
14 \pm 4 \\
24 \pm 6\end{array}$ & $\begin{array}{l}15 \pm 5 \\
4.4 \pm 1 \\
42 \pm 8 \\
3.0 \pm 1 \\
16 \pm 5\end{array}$ & $\begin{array}{l}1.2 \pm 0.8 \\
0.7 \pm 0.05 \\
1.1 \pm 0.2 \\
14 \pm 6 \\
0.2 \pm 0.03\end{array}$ & $\begin{array}{r}9 \pm 2 \\
0.7 \pm 3 \\
25 \pm 6 \\
2.6 \pm 1 \\
54 \pm 8\end{array}$ & & \\
\hline \multicolumn{7}{|l|}{ Diabetic BB rat: spleen $(n=3)$} \\
\hline & \multicolumn{2}{|c|}{ Effector cell phenotype (\%) } & & & & \\
\hline & $\mathrm{CD} 4$ & CD8 & $\mathrm{DN}$ & NK & & \\
\hline Enrichment procedure for: & & & & & $\begin{array}{l}\text { Cytotox } \\
10: 1^{6}\end{array}$ & $\begin{array}{c}\text { ty }(\%) \\
20: 1\end{array}$ \\
\hline Total mononuciear cells & $16 \pm 5$ & $29 \pm 5.3$ & $6 \pm 2.1$ & $9.0 \pm 1.2$ & $31 \pm 7.9$ & $43 \pm 8.4$ \\
\hline $\mathrm{CD}^{+}{ }^{+}$cells $^{\mathrm{a}}$ & $44 \pm 12$ & - & - & - & $31 \pm 11$ & $42 \pm 3.0$ \\
\hline CD $8^{+} \mathrm{T}_{\text {cells }}^{\mathrm{a}}$ & - & $6.3 \pm 2$ & - & - & $34 \pm 10$ & $47 \pm 4.3$ \\
\hline Double-negative T Cells ${ }^{\mathrm{a}}$ & - & - & $14 \pm 8$ & - & $34 \pm 9.7$ & $43 \pm 2.8$ \\
\hline Natural killer cells & - & - & - & $33 \pm 12$ & $25 \pm 11$ & $38 \pm 2.9$ \\
\hline
\end{tabular}

a of $\mathrm{TCR}^{+} \mathrm{T}$ cells

${ }^{\mathrm{b}}$ Effector : Target ratio

tecture is destroyed. We conclude that our diabetic rat islet data reflect the final infiltrate just prior to the islet disruption observed histologically. We also know that islets derived at this stage are also glucose hyper-responsive for insulin secretion despite the intense inflammation [16]. Our non-diabetic rat islet data reflect an earlier stage in the process, which for T-cell subsets appears phenotypically stable both before and after diabetes onset, despite the presence of inflamed islets in animals that are not destined to become diabetic. These points are supported by the observations that $\mathrm{DN} T$ cells in $\mathrm{BB}$ rat islets are a prominent cell type, as described in $\mathrm{BB}$ rat spleen [8] and NOD islets [9]. These considerations indicate the need for functional data to be performed in the key in situ subsets observed (see below.)

T cells are described as the major cell type in islets during the later stages of inflammation $[1,3,4,7]$. When phenotyping splenic $\mathrm{T}$ cells in BB rats, we noted a population of $\mathrm{CD}^{-}$, TCR alpha/beta ${ }^{+} \mathrm{T}$ cells [8]. Thus in these spleen studies, attempts to be definitively quantitative should not be made when adding T-cell subsets using different total T-cell monoclonal antibodies. Rat T-cell subsets have not been systematically studied in islets, but activated $T$ cells identified by IL-2 receptor and Ia expressing cells are suggested to be present during the later stages of prediabetes $[2,3]$. Although we were unable to directly and specifically identify activated $T$ cells as a major cell type in inflamed islets, we did observe activated $T$ cells as a major subset present in BB rat spleen using the same methods [8]. Our islet-activated T-cell data are supported by the observation of a minimal number of cells (3-4/islet) expressing cytokine mRNA in DP islets and expression of cytokines by $T$ cells was not observed [17].

Double-negative (DN) T cells have not been previously described in BB rat islets, and our results both in the NOD mouse [9] and BB rat show that this subset rep-

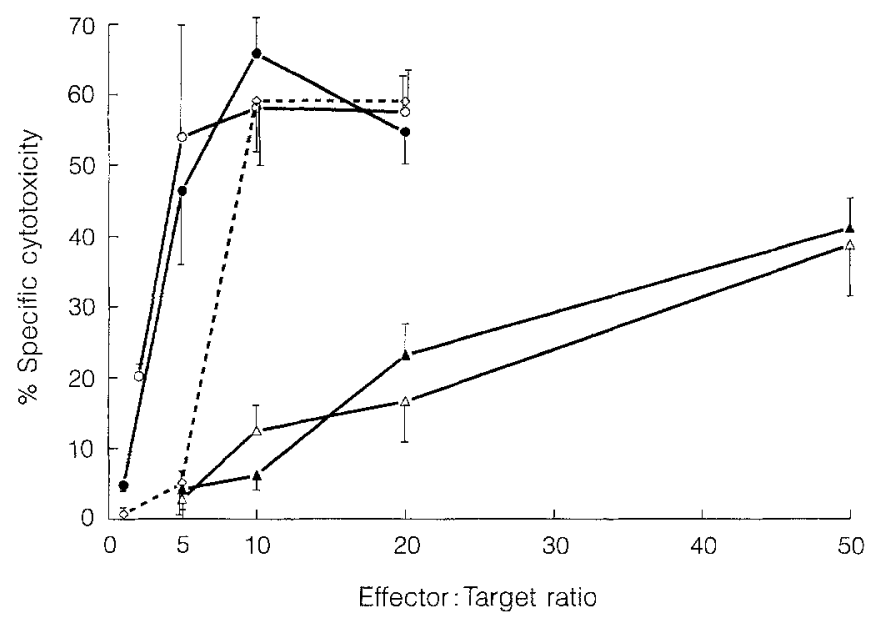

Fig.6. Cytolytic analyses of in situ islet derived effector cells derived from diabetic (,$n=4)$ and non-diabetic diabetes prone (DP) BB rats $(O, n=4)$ compared to splenic effector cells from diabetic $(\boldsymbol{\Lambda}$, $n=3)$ and non-diabetic $(\triangle, n=3) \mathrm{DP} B \mathrm{~B}$ rats using Sprague Dawley islet target cells. Non-islet rat ileal epithelial target cell cytolysis mediated by diabetic DP BB rat islet effector cells is also shown $(\diamond$, $n=3$ ). Bars indicate SEM

resents about $30 \%$ of the islet $\mathrm{T}$-cell population. This is similar to the relative percentages of DN $T$ cells in NOD and $\mathrm{BB}$ rat spleen at diabetes onset $[8,9]$. The role of DN $T$ cells is unclear, but in murine and human lupus, DN T cells have been described as providing B lymphocyte help in generating pathogenic glomerular basement membrane antibodies $[18,19]$. DN T cells have also been described as having abnormal $\mathrm{K}^{+}$channels in several murine autoimmune models including diabetes [20]. Thus, now that DN T cells are recognized as phenotypically important in in situ islets, functional studies should determine their role in diabetes pathogenesis. A recent study in nor- 
mal mice suggests that DN T cells may escape thymic elimination and thus become potentially important autoreactive T-cell clones [21]. Our DN T cell results in DP BB rat spleen compared to DR Wistar rats and Wistar Furth rats also suggest the escape of DN T cells during the process that also depletes $\mathrm{CD} 4^{+}$and $\mathrm{CD} 8^{+} \mathrm{T}$ cells in the DP strain of $\mathrm{BB}$ rats [8]. CD8 ${ }^{+} \mathrm{T}$ cells in islets represent about $20 \%$ of the T-cell subset population, which is distinctly more than the mean levels observed in BB rat spleen at diabetes onset. We have used similar quantitative methods to also identify in situ islet $\mathrm{T}$-cell receptor usage in early and later stages of diabetes in the NOD mouse [22].

The quantitative mononuclear cell hierarchy of cells derived from in situ islets is as follows: (a) NK cells are a predominate cell type present both before and after diabetes onset, (b) T cells are another predominate cell type, (c) the T-cell subset hierarchy is $\mathrm{CD} 4^{+}>\mathrm{DN}$ T cells $>\mathrm{CD} 8^{-} \mathrm{T}$ cells and $(\mathrm{d})$ activated $\mathrm{T}$ cells, macrophage and $B$ cells, although present, appear at significantly lower percentages. Quantitative spleen cell analysis in nondiabetic and diabetic DP BB rats also indicate a clear hierarchy of cells: $\mathrm{B}$ cells $>\mathrm{T}$ cells $(\mathrm{CD} 4>\mathrm{DN}>\mathrm{CD} 8)>\mathrm{NK}$ cells $>$ macrophages [8]. These data indicate that previous spleen cell data should be used with caution when making comparisons related to the actual cellular events involved in the destruction of pancratic islets in BB rats. The likelihood of not observing other cell types present in islets is low, since both the major cell type and T-cell subset percentages are virtually $100 \%$ of the mononuclear immune cells present in islet infiltrates. It is also unlikely that our methods incorrectly assess the relative percentages of in situ islet immune cells present, since (a) our results are highly reproducible, (b) virtually all immune cells previously described in islets are detected by our methods, (c) we have described immune cells not previously reported in islets, (d) we have used CD5 monoclonals with similar results to TCR alpha/beta monoclonals (data not shown), (e) using identical methods, our endocrine cell subtype percentages agree with other reports [23] and (f) islet cell surface markers remain intact using identical methods [23].

Functional studies of a quantitative nature using cells derived from inflamed pancreatic islets of diabetic BB rats have not been described. We have recently reported in situ islet cytolytic data in the NOD model [9]. Our cytolytic studies in diabetic and non-diabetic DP BB rats and diabetic NOD mice indicate that total in situ islet derived effector cells are much stronger mediators of islet target cell destruction than effector cells derived from the spleen. The cytolytic behaviour expressed appears nonspecific with respect to MHC but is relatively tissue specific. If one assumes about $2500-5000$ beta cells per islet, and if nearly 1000 immune cells are present per islet, then effector:target ratios are effectively $0.5: 1$. Because of effector cell clustering, this ratio may go up to less than $5: 1$; thus the killing observed in vitro at less than $5: 1$ effector: target ratios may be more valid than ratios greater than 5 . Killing may thus be tissue specific at low effector:target ratios. Since the predominate cell subsets in in situ islets are NK and $\mathrm{T}$ cells in the $\mathrm{BB}$ rat, perhaps these cells are the major mediators of islet cell destruction. This to some extent may also explain the lack of MHC restriction on islet cytolytic events. Our functional data are consistent with those non-restricted cytolytic data observed using spleen effector cells in previous studies $[24,25]$. This killing is unlikely to be alloreactivity since similar results are obtained using Wistar Furth or DP islet target cells. Our previously reported data of non-restricted splenic derived macrophage-mediated islet cytolysis could be related to total islet effector cell killing reported herein [24]. These data do not indicate which cell subtype(s) is (are) the major islet effector cell. Thus further studies were performed to determine which cell subtypes are most cytolytic. Non-lymphopoenic spleen cells were successfully enriched and thus studies were attempted in the spleen of the lymphopoenic DP BB strain. Preliminary studies showed some enrichment of spleen cell subtypes but no relative enhancement of in vitro islet immune cell subset cytolytic activity. Thus using these methods, insufficient cells are present to effectively analyse immune cell subset function.

In summary, quantitative phenotypic and functional analyses of in situ islet cells may be a more direct method for determining the pathogenic mechanisms involved in diabetes onset. These methods may provide more rational treatment strategies for use in diabetes.

Acknowledgements. The authors thank Mr. K. Huang, Mr. R. Garcia, Ms C. Kim, Mr. L. Reingerz and Ms L. Vega for their excellent technical assistance, to Ms S. Feighn for editing and to Ms K. Posell for preparation of the manuscript.

\section{References}

1. Dean BM, Walker R, Bone AJ, Baird JD, Cooke A (1985) Prediabetes in the spontaneously diabetic $\mathrm{BB} / \mathrm{E}$ rat: lymphocyte subpopulations in the pancreatic infiltrate and expression of rat MHC class II molecules in endocrine cells. Diabetologia 28: 464 466

2. Signore A, Parman A, Pozzilli P, Andreani D, Beverly PCL (1987) Detection of activated lymphocytes in endocrine pancreas of $\mathrm{BB} / \mathrm{W}$ rats by injection of ${ }^{123} \mathrm{I}$-interleukin-2: an early sign. of type 1 diabetes. Lancet II: 537-540

3. Weringer EJ, Like AA (1988) Identification of T cell subsets and class I and class II antigen expression in islet grafts and pancreatic islets of diabetic Biobreeding/ Worcester Rats. Am J Pathol 132: $292-303$

4. Walker R, Bone AJ, Cooke A, Baird JD (1988) Distinct macrophage subpopulations in pancreas of prediabetic $\mathrm{BB} / \mathrm{E}$ rats. Diabetes 37: 1301-1304

5. Lee KU, Kim MK, Amano K et al. (1988) Preferential infiltra tion of macrophages during early stages of insulitis in diabetesprone $B B$ rats. Diabetes 37: 1053-1058

6. Hanenberg H, Kolb-Bachofen V, Kantwerk-Funke G, Kolb H (1989) Macrophage infiltration precedes and is a prerequisite for lymphocytic insulitis in pancreatic islets of pre-diabetic BB rats. Diabetologia 32: 126-134

7. Voorbij HAM, Jeucken PHM, Kabel PJ, De Haan M, Drexhage HA (1989) Dendritic cells and scavenger macrophages in pancreatic islets of prediabetic BB rats. Diabetes 38: 1623-1629

8. Hosszufalusi N, Chan EK, Granger GA, Charles MA (1992) Quantitative analyses comparing all major spleen cell phenotypes in BB and normal rats: autoimmune balance abnormalities associated with prediabetes and diabetes. J Autoimmun 5: 305318 
9. Formby M, Hosszufalusi N, Chan E et al. (1992) Quantitative and functional analysis of spleen and in situ islet immune cells before and after diabetes in the NOD mouse. Autoimmunity 12 : 95-102

10. Charles MA, Lawecki J, Pictet R, Grodsky GM (1975) Insulin secretion interrelationships of glucose, cyclic adenosine $3^{\prime}: 5^{\prime}$ monophosphate, and calcium. J Biol Chem 250: 61346140

11. Charles MA, Suzuki M, Slater L, Waldeck N, Ong K (1983) Immune islet killing mechanisms associated with insulin-dependent diabetes: three rabbit antibody-mediated islet cell cytotoxicity models. Diabetologia 25: 348-354

12. Charles MA, Sharma B, Dodson LE et al. (1984) Mechanism of rat pancreatic islet allograft rejection. Diabetes Res 1: 95-103

13. Mason DW, Penhale WJ, Sedgwick JD (1987) Preparation of lymphocyte subpopulations. In: Klaus GGB (ed) Lymphocytes: a practical approach. IRL Press Ltd, Oxford, pp 48-51

14. Van Den Brink MR, Hunt LE, Hiserodt JC (1990) In vivo treatment with monoclonal antibody 3.2 .3 selectively eliminates natural killer cells in rats. J Exp Med 171: 197-201

15. Quaroni A, Wands J, Trelstad RL et al. (1979) Epithelioid cell cultures from rat small intestine: characterization by morphologic and immunologic criteria. J Cell Biol 80: 248-265

16. Teruya M, Takei S, Forrest LE, Grunewald A, Chan EK, Charles MA (1993) Pancreatic islet function in nondiabetic and diabetic $\mathrm{BB}$ rats. Diabetes (in press)

17. Jiang Z, Woda BA (1991) Cytokine gene expression in the islet of the diabetic Biobreeding/Worcester rat. J Immunol 146: 29902994

18. Shivakumar S, Tsokos GC, Datta SK (1989) T cell receptor alpha/beta expressing double-negative $\left(\mathrm{CD} 4^{-} \mathrm{CD} 8^{-}\right)$and $\mathrm{CD} 4^{+} \mathrm{T}$ helper cells in humans augment the production of pathogenic anti-DNA autoantibodies associated with lupus nephritis. J Immunol 143: 103-112

19. Sainis K, Datta SK (1988) CD4 ${ }^{+}$T cell lines with selective patterns of autoreactivity as well as $\mathrm{CD} 4^{-} \mathrm{CD} 8^{-} \mathrm{T}$ helper cell lines augment the production of idiotypes shared by pathogenic antiDNA autoantibodies in the NZB X SWR model of lupus nephritis. J Immunol 140: 2215-2221

20. Chandy KG, Cahalan MD, Grissmer S (1990) Autoimmune diseases linked to abnormal $\mathrm{K}^{+}$channel expression in double-negative CD4-CD8- T cells. Eur J Immunol 20: 747-751

21. Prud'homme GJ, Bocarro DC, Luke ECH (1991) Clonal deletion and autoreactivity in extrathymic $\mathrm{CD}^{-}{ }^{-} \mathrm{CD}^{-}$(double negative) T cell receptor- $\alpha / \beta$ T-cells. J Immunol 147:3314-3318

22. Toyoda H, Redford A, Magalong D et al. (1992) In situ islet T cell receptor (TCR) variable region gene usage in the nonobese diabetic (NOD) mouse. Immun Lett 32: 241-246

23. Lautenschlager I, Inkinen K, Taskinen E, Charles MA, Hayry P (1989) Major histocompatibility complex protein expression on pancreas and pancreatic islet endocrine cell subsets. Am J Path 135: 1129-1137

24. Nagy MV, Chan E, Teruya M, Forrest LE, Likhite V, Charles MA (1989) Macrophage-mediated islet cell cytotoxicity in BB rats. Diabetes 38: 1329-1331

25. McKay P, Jacobson J, Rabinovitch A (1986) Spontaneous diabetes mellitus in the Bio-Breeding/Worcester Rat. Evidence in vitro for natural killer cell lysis of islet cells. J Clin Invest 77 916-924

Received: 28 December 1992

and in revised form: 16 June 1993

Dr. M.A.Charles

Rm. C250, Medical Sciences Bldg. I

Diabetes Research Program

College of Medicine

University of California

Irvine, CA 92717

USA 